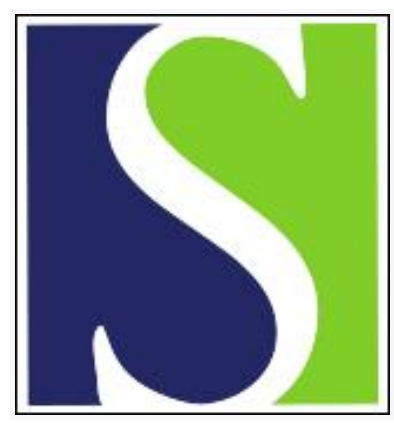

Scand J Work Environ Health 2013;39(1):106-111

https://doi.org/10.5271/sjweh.3284

Published online: 22 Feb 2012, Issue date: Jan 2013

Mortality attributable to occupational exposure in Sweden

by Järvholm B, Reuterwall C, Bystedt J

Affiliation: Department of Public Health and Clinical Medicine, Umeå University, 90187 Umeå, Sweden. bengt.jarvholm @envmed.umu.se

Refers to the following texts of the Journal: 2002;28(1):58-63

2001;27(3):161-213 2012;38(1):19-26 2004;30(2):85-128

The following article refers to this text: 2020;46(5):542-551

Key terms: asthma; attributable fraction; cancer; chronic obstructive pulmonary disease; etiology; exposure; mortality; myocardial infarction; occupational exposure; occupational exposure; pneumoconiosis; Sweden; work-related

This article in PubMed: www.ncbi.nlm.nih.gov/pubmed/22358144 


\title{
Mortality attributable to occupational exposure in Sweden
}

\author{
by Bengt Järvholm, MD, PhD, ${ }^{1}$ Christina Reuterwall, PhD, ${ }^{1}$ Jennie Bystedt, $M{ }^{2}{ }^{2}$
}

Järvholm B, Reuterwall C, Bystedt J. Mortality attributable to occupational exposure in Sweden. Scand J Work Environ Health. 2013;39(1):106-111. doi:10.5271/sjweh.3284

Objective The aim of this study was to estimate the mortality from cancer, cardiovascular, and respiratory diseases attributable to occupational exposure in Sweden.

Methods Estimates were calculated for men and women separately, and we considered only deaths between 25-74 years of age. We considered cancer exposures/sites classified as 1 or 2 a according to the International Agency for Research on Cancer (IARC). Acute myocardial infarction was the only included cardiovascular disease. Respiratory diseases comprised chronic obstructive pulmonary disease (COPD) asthma, pneumoconiosis, and alveolitis. All deaths of pneumoconiosis and alveolitis were considered work-related. Estimates were based on Swedish mortality in 2007.

Results In total, we estimate there are about 800 work-related deaths per year in the studied causes. The majority are due to acute myocardial infarction, with 126 deaths among women and 337 deaths among men attributable to job strain, shift work, exhaust gases, combustion products, or environmental tobacco smoke (ETS). There are 99 respiratory disease-related deaths, the vast majority from COPD $(\mathrm{N}=92)$. In total, 270 cancer deaths are estimated to be work-related. For men, half of the cases are attributed to asbestos exposure.

Conclusions Our results indicate that preventive measures to decrease occupational mortality should consider factors associated with myocardial infarction such as job strain, shift work, and exhaust gases from vehicles and combustion products. Exposures to factors associated with COPD, such as dust, would also appear important to prevent.

Key terms asthma; attributable fraction; cancer; chronic obstructive pulmonary disease; etiology; myocardial infarction; pneumoconiosis; work-related.

It has been estimated that in 2002 globally about 2 million deaths per year were attributed to occupational related diseases and 960000 to fatal occupational accidents (1). The risk and type of disease will vary between countries and time depending on exposure and the size of the exposed population. A Finnish study estimated that in 1996 there were about 1800 work-related deaths in Finland, of which about 80 were from accidents and the rest from diseases, ie, work-related fatalities were estimated to about $7 \%$ of all work-related deaths (2). A recent UK study estimated that $5.3 \%$ of all cancer deaths in Britain were work-related (3). The Swedish Cancer Committee estimated in the 1980 s that about $2 \%$ of cancer cases were work-related (4).

The exposure and risks have changed considerably over time in Sweden. Reporting of occupational fatal accidents has been mandatory since the mid-1950s and the number of deaths has decreased from about 400 in 1955 to approximately 50 per year during the last years (ie, 40 cases in 2009 and 54 cases in 2010). Furthermore, the number of persons working in manufacturing has decreased while the service sector has increased in size. The objective of the present study was to estimate the number of work-related deaths from cancer and cardiovascular and respiratory diseases in Sweden today as a basis for forming future preventive strategies.

\section{Methods}

In order to estimate occupational mortality, criteria are required to decide which diseases can be considered as being caused by occupational factors. For cancer,

\footnotetext{
1 Department of Public Health and Clinical Medicine, Occupational and Environmental Medicine, Umeå University, Umeå, Sweden.

2 Sundsvalls Hospital, Sundsvall, Sweden.

Correspondence to: Bengt Järvholm, Department of Public Health and Clinical Medicine, Umeå University, 90187 Umeå, Sweden. [E-mail: bengt.jarvholm@envmed.umu.se]
} 
there are reviews from authorities like the International Agency for Research on Cancer (IARC), but for other diseases different criteria must be used. Another issue is to decide what fraction of each of those diseases is attributable to different occupational factors. In our study, we used estimates from published reviews and national studies or, for a few diseases, we considered all deaths attributable to occupational factors.

Cancer. For cancer, we considered sites/exposure classified as 1 or $2 \mathrm{a}$ according to IARC and the same sites as a recent British study (3). For cancer sites, except lung cancer and mesothelioma, there are rather few estimates of work-related attributable fractions (AF) in the literature. We primarily used AF from a Finnish and British study as we considered the work environment in those countries fairly similar to that of Sweden $(2,3)$. With the exception of larynx and lung cancer, we applied the AF estimates from the British study when calculating our estimates of work-related cancer mortality in the Swedish population. We preferred the British estimates over the Finnish as they were more clearly explained. For lung cancer, we used results from Swedish case reference studies, and we used the Finnish estimates for larynx cancer as they were from a Swedish case referent study (5).

Respiratory diseases. In our analysis, we regarded all deaths resulting from pneumoconiosis and hypersensitivity pneumonitis as work-related. The only respiratory diseases we considered in our analysis apart from pneumoconiosis and alveolitis were asthma and chronic obstructive pulmonary disease (COPD). There are some studies estimating the AF for work-related asthma; a recent study concluded that $17.6 \%$ of adult-onset asthma was work-related (6). An expert group of the American Thoracic Society (ATS) estimated the work-related AF for COPD to be $15 \%$ in 2003 (7). As none of these estimates differentiated between women and men, we also used the estimate for both sexes.

Cardiovascular diseases. We chose to consider only acute myocardial infarction as there are better established work-related factors for this diagnosis. We also regarded the evidence for a causal association with work to be more established for myocardial infarction than for other cardiovascular diseases, eg, stroke. Several studies have shown an increased risk in cardiovascular diseases and "stress", the latter has been defined in different ways between studies. The international study "Interheart" found that $9 \%$ of acute myocardial infarction cases could be attributed to occupational stress (8). Reviews have also found an association, especially among men (9, 10). Several studies have found an association between air pollution in the general environment and cardiovas- cular diseases due to exposure for particulates coming from, for example, motor exhausts and combustion (11). Occupational studies also indicate an increased risk for cardiovascular disease and particulates, however the origin of such particulates is more variable (12). In our analysis of work-related acute myocardial infarction, we included the following risk factors: irregular working hours including shift work (abbreviated here to "shift work"), job strain, motor exhausts, combustion products and ETS. Also causes other than those mentioned above (eg, noise) are discussed as being work-related but the evidence for causality is limited (13). We considered that the factors we selected were somewhat more established as being work-related than noise, but our choice of factors was also influenced by the availability of good AF estimates for job strain, shift work, motor exhausts, combustion products, and ETS from a national study (14-17). A Finnish study included shift work, noise, motor exhausts and ETS as work-related risk factors for ischemic heart disease (2). The total AF for all exposure linked to myocardial infarction was estimated by adding the estimates for the respective exposure.

There are two methods to estimate the AF of a disease. It can be estimated from a population-based casereferent study [(proportion of cases that are exposed) $\times(\mathrm{RR}-1) / \mathrm{RR}]$. Alternatively, risk estimated from an exposed (occupational) population can be used in conjunction with estimates of the fraction of exposed persons in the general population (18). We have prioritized the use of estimates from population-based case-referent studies. Where these were not available, we used estimates of AF from two other studies from the UK and Finland respectively $(2,3)$.

For each disease, the number of attributable cases has been calculated from $\mathrm{AF}$ and the number of deaths in Sweden in 2007. The numbers of deaths will strongly depend on the oldest group especially if similar AF is used for all ages. There are rarely good data to yield separate estimates of AF for different age groups. For myocardial infarction, we did not have good national estimates for ages $>75$ years. Therefore, we restricted the analysis to 25-74 years of age. Separate estimates of the number of work-related deaths were calculated for women and men.

\section{Results}

In total, we estimated 207.2 male and 62.7 female cancer deaths to be work-related (table 1). Of these, 133.7 deaths (115.9 among men and 17.8 among women) were lung cancer deaths. There are four Swedish populationbased case-referent studies of lung cancer among men where cases and referents have been interviewed (19- 
22). All were adjusted for smoking habits. Three studies $(19,21,22)$ found an AF of $8-10 \%$, while the study by Järvholm et al (20) found an AF of $16 \%$. The power of the studies is modest so the variation of AF between studies may be random, but it may also reflect differences in occupational exposure. The study by Järvholm et al (20) was carried out in the city of Gothenburg, which has had large shipyards and thus a high exposure to asbestos compared to most other regions in Sweden. Axelson (23) estimated the AF to be $24-28 \%$ based on an analysis of census data. The British and Finnish studies estimated occupational exposure to asbestos to cause a considerable part of the work-related cases of lung cancer $(41 \%$ for men and women together in the British study and $48 \%$ for men and $11 \%$ for women in the Finnish study).

Some studies have indicated that the number of workrelated lung cancer deaths attributed to asbestos is similar in size to the number of work-related mesothelioma deaths (24). There were in total 105 male deaths of mesothelioma in 2007 in Sweden, of which 60 victims were $25-74$ years old. We attributed $90 \%$ of these deaths to asbestos, the same proportion as in the Finnish and British study. Thus, applying the ratio 1:1 to lung cancer, mesothelioma would indicate about 100 asbestos-related male deaths from lung cancer in all ages. The British and Finnish studies estimated that $40-50 \%$ of male workrelated lung cancer is due to asbestos exposure. If we assume that $50 \%$ of Swedish male work-related lung cancer is caused by asbestos exposure, there would be about 200 cases per year in all ages. Such an estimate of work-related male lung cancer corresponds to an $\mathrm{AF}$ of $11.2 \%$. This estimate is in accordance with the estimates from earlier mentioned Swedish population-based casereferent studies and was used in our calculations. Thus, we estimated the $\mathrm{AF}$ for male deaths from lung cancer to be $11.2 \%$ (ie, 115.9 cases in the age group $25-74$ years). Estimation of female lung cancer related to occupational exposure of asbestos using the relation to mesothelioma $(1: 1)$ indicates 4.5 cases in all ages (18 deaths in mesothelioma of which $25 \%$ were estimated to be work-related to asbestos). According to Nurminen \& Karjalainen (2), ETS is an important factor for female work-related lung cancer ( $\mathrm{AF}=2.0 \%)$, while Rushton et al (3) attributed ETS to $0.8 \%$ (not stratified for sex). In $1993,10 \%$ of Swedish women reported occupational ETS exposure, compared to just $5 \%$ in 2007 (25). A relative risk of ETS around 1.25 among non-smokers and an exposure prevalence of $5 \%$ indicates an $\mathrm{AF}$ of $1.2 \%$ among non-smoking women $[0.05 \times(1.25-1) /(1+0.05 \times[1.25-1])=1.2 \%]$. If it is assumed that around $80 \%$ of women are occupationally active (the approximate percentage in Sweden since 1980s) and 30\% of the female lung cancer cases occur among non-smokers, this would indicate around 5 cases. If the exposure prevalence is $10 \%$ it would yield about
Table 1. Estimated number of work-related deaths from cancer, and cardiovascular and respiratory diseases in Sweden for men and women aged 25-74 years in 2007. [AF=attributable fraction; COPD=chronic obstructive pulmonary disease; $I C D=$ International Classification of Diseases]

\begin{tabular}{|c|c|c|c|c|c|}
\hline \multirow[t]{2}{*}{ Disease } & \multirow[t]{2}{*}{$($ ICD 10) } & \multicolumn{2}{|c|}{$\mathrm{AF}(\%)$} & \multicolumn{2}{|c|}{ Cases } \\
\hline & & Women & Men & Women & Men \\
\hline Cancer (total) & & & & 62.7 & 207.2 \\
\hline Esophagus & $\mathrm{C} 15$ & $1.1^{\mathrm{a}}$ & $3.3^{\mathrm{a}}$ & 0.6 & 5.8 \\
\hline Stomach & C16 & $0.3^{a}$ & $3.0^{\mathrm{a}}$ & 0.6 & 5.7 \\
\hline Liver & $\mathrm{C} 22$ & $0.1^{\text {a }}$ & $0.2^{\mathrm{a}}$ & 0.1 & 0.4 \\
\hline Nose, nasal sinuses & C30-31 & $20.1^{\text {a }}$ & $46.0^{\mathrm{a}}$ & 1.0 & 3.2 \\
\hline Larynx & C32 & $0.5^{b}$ & $9.3^{b}$ & 0 & 3.0 \\
\hline Lung & C34 & $1.8^{c}$ & $11.2^{c}$ & 17.8 & 115.9 \\
\hline Skin & C44 & $1.1^{\mathrm{b}}$ & $7.1^{\mathrm{b}}$ & 0 & 0.9 \\
\hline Mesothelioma & C45 & $25.0^{c}$ & $90.0^{c}$ & 2.3 & 54.0 \\
\hline Urinary bladder & C67 & $1.9^{\mathrm{b}}$ & $7.1^{\mathrm{b}}$ & 1.1 & 11.3 \\
\hline Kidney & C64 & $0.04^{\mathrm{a}}$ & $0.04^{\mathrm{a}}$ & 0.0 & 0.0 \\
\hline Breast & $\mathrm{C} 50$ & $4.6^{\mathrm{a}}$ & - & 34.5 & - \\
\hline Cervix uteri & C53 & $0.7^{\text {a }}$ & - & 0.8 & - \\
\hline Ovary & C56 & $0.5^{\mathrm{a}}$ & - & 1.8 & - \\
\hline Brain & C71 & $0.1^{\mathrm{a}}$ & $0.5^{\mathrm{a}}$ & 0.2 & 1.6 \\
\hline Non-Hodgkin lymphoma & C82 & $1.1^{\mathrm{a}}$ & $2.1^{\mathrm{a}}$ & 1.2 & 3.7 \\
\hline Leukemia & C91-95 & $0.5^{a}$ & $0.9^{a}$ & 0.7 & 1.7 \\
\hline \multicolumn{2}{|c|}{ Respiratory diseases (total) } & & & 52.3 & 46.6 \\
\hline Pneumoconiosis & $\mathrm{J} 60-65$ & $100^{c}$ & $100^{c}$ & 0 & $3^{d}$ \\
\hline $\begin{array}{l}\text { Hypersensitivity } \\
\text { pneumonitis }\end{array}$ & J67 & $100^{c}$ & $100^{c}$ & 0 & 0 \\
\hline Asthma & J45-46 & $17.6^{c}$ & $17.6^{\mathrm{c}}$ & 1.9 & 2.5 \\
\hline COPD & J44 & $15.0^{c}$ & $15.0^{c}$ & 50.4 & 41.1 \\
\hline Acute myocardial infarction & 121 & $23.0^{c}$ & $20.1^{c}$ & 125.6 & 336.9 \\
\hline Total & & & & 240.6 & 590.7 \\
\hline
\end{tabular}

a According to Rushton et al, 2010 (3).

${ }^{\mathrm{b}}$ According to Nurminen \& Karjalainen, 2001 (2).

c See text for references.

${ }^{\mathrm{d}}$ Caused by asbestos, coal dust and dust of unknown origin.

10 cases. Thus, only asbestos and ETS would together cause about 10-15 lung cancer deaths among women of all ages. Both Nurminen \& Karjalainen (2) and Rushton et al (3) estimated the $\mathrm{AF}$ in female lung cancer to be $5.3 \%$, which corresponds to 52 deaths in Sweden. In our calculation, we used 30 cases in all ages or $3.1 \%$, which is approximately the mean between an estimate based on an EF of 5.3\% and the lower estimate based on ETS and asbestos (10 cases).

Overall lung cancer and mesothelioma constituted $32 \%$ of work-related cancer cases among women and $82 \%$ among men. Work-related breast cancer was 55\% of all work-related cancer cases among women (table 1).

There were in total 14 pneumoconiosis deaths (13 men and 1 woman) and one hypersensitivity pneumonitis death (1 woman) in Sweden in 2007. Of these, three were $\leq 74$ years (men with asbestosis, coal workers' pneumoconiosis, and unspecified pneumoconiosis respectively) (table 1).

The estimated number of work-related COPD deaths was much higher than asthma (about 90 versus 4 cases).

The estimated AF for acute myocardial infarction due to job strain was 14.7 and 6.7 for women and men, 
respectively. The AF for working on non-regular times including shift work was $3.8 \%$ for women and $4.1 \%$ for men (15). For motor exhaust, the two highest categories of cumulative exposure in the population study ( $23 \%$ of all cases, relative risks 1.2 and 1.3) indicated an AF of 3.8-5.3. Stockholm is a large city with a lot of traffic and the risk for the entire country is probably somewhat lower. Therefore, we used a lower AF (3.5\%) in our calculations, the same AF for both women and men. For other combustion products, the study reported that the $\mathrm{AF}$ was $4.4 \%$ for men while no estimate was given for women (14). The jobs classified in the study as being exposed to combustion products (eg, engineers, firefighters and blacksmiths) are much more common among men than women in Sweden. Thus, for women we used an AF of 0 for combustion products. For ETS, the population-based case-referent study found a relative risk of 1.3 for women and 1.4 for men (17). According to the Swedish work environment survey in 2007, $4 \%$ of women and $5 \%$ of men are exposed to ETS at the job (26). Thus, we estimated AF for occupational ETS to be $0.95 \%$ and $1.4 \%$ among women and men, respectively.

Thus, among all persons aged 25-74 years who died of cancer, respiratory diseases, or acute myocardial infarction in 2007 in Sweden, we estimated that 240.6 and 590.7 cases were work-related among women and men, respectively. This corresponds to $2.5 \%$ and $3.9 \%$ of all female and male deaths, respectively. The major cause of death was acute myocardial infarction, which constituted $52 \%$ and $57 \%$ of these work-related deaths among women and men, respectively.

\section{Discussion}

The number of work-related deaths is dependent on which diseases are considered to be work-related and the fraction thereof attributed to work. The Swedish Work Environment Authority requested that this study be conducted, and the results can be used as one component of priority processes of preventive work. Therefore, it is important that the criteria for inclusion are similar for different causes and diseases. We have been conservative in regarding diseases as work-related, and we have also used conservative estimates of the AF. Compared to the Finnish study (2), we included fewer diseases and sometimes lower AF. They concluded that $10 \%$ of male deaths were work-related while our estimate was $3.9 \%$. However, our estimate is slightly higher for women ( $2.5 \%$ versus $2 \%)$. We included job strain as a cause of myocardial infarction and work during non-regular time as a cause of breast cancer, which they did not. Excluding those associations would decrease our estimate for women to only $1.3 \%$.

For all cancer sites together, our estimate for men is lower than those of the British and Finnish studies $(2,3)$. This is mainly due to the lower estimate for lung cancer (AF $11.2 \%$ in our study versus 21.1 and $29.0 \%$, respectively). However, our estimate is in accordance with the four Swedish population-based case-referent studies. A recent Italian population-based case-referent study found that just $4.9 \%$ of lung cancer cases were work-related (27). Driscoll et al (28) estimated an AF of $12 \%$ and $4 \%$ among men and women, respectively, in a country like Sweden (28). Thus, our estimate is somewhat conservative but in a range similar to other estimates.

Work-related chronic diseases are usually an effect of exposure over several years or decades. Furthermore, the concentrations of the harmful factor and the exposed population may vary over time making estimations very complex and depending on a number of assumptions. The risk estimates of lung cancer and myocardial infarction are from recent decades. We used the present ETS exposure prevalence to estimate the number of myocardial deaths attributable to ETS exposure; however, we do not know the critical time window for such exposure. For COPD, we used international population estimates that may depend on smoking prevalence, which change over time and between countries.

COPD was the major cause for work-related respiratory diseases. During recent years, exposures other than tobacco smoke have been acknowledged as a cause of COPD, among them occupational exposure to air pollutants $(7,29,30)$. Pneumoconiosis is today a rare cause of death in Sweden. In 2007, there were a total of 4 deaths in silicosis and all cases were $>85$ years of age.

A major finding in our study is the importance of acute myocardial infarction as a work-related cause of death. According to our calculations, it constituted $>50 \%$ of the work-related deaths of 25-74-year olds in Sweden in 2007. Even if our review does not include all diseases or fatal occupational accidents ( 75 deaths in 2007), cardiovascular diseases seem to be a major workrelated disease to consider in preventive work. We only included acute myocardial infarction because we felt there was strong evidence for that disease. It is reasonable to assume that also some cases of chronic ischemic heart disease (IHD) are work-related. If we regard the same exposure factors and apply the same AF to IHD as used in calculations for work-related myocardial infarction, the number of work-related deaths in cardiovascular diseases would double. There are also some indications that psychosocial factors increase the risk for stroke (31). We have used job strain as one measure for work-related stress. There are several studies indicating a relation between job strain and IHD including myocardial infarction and more recent studies attribute the risk mainly to demands (10).

We used population-based case-referent studies 
when possible to estimate the AF. It has been argued that this gives a more reliable estimate than using relative risks from cohort studies and estimates the exposure prevalence in the population (32). However, we have not adjusted for overlapping exposure, ie, the same individual may be exposed to several factors. Thus, AF for acute myocardial infarction may be overestimated when we add all AF for the different exposures (eg, some persons have probably been exposed to shift work as well as job strain and combustion products concurrently or during different parts of their occupational career). We do not have information to adjust for that. We applied the same AF for men and women in the estimations for asthma and COPD as the published estimates are not stratified for gender. The work environment for men and women differs in Sweden. More Swedish men than women work in manufacturing, mines, and construction. If a major cause of work-related COPD is dust, one would expect different estimates for men and women. Whether our estimate means an underestimation for men or overestimation for women is uncertain. We used the estimates of AF for onset of adult asthma, while asthma-related deaths may be more common among persons who suffered from severe asthma as children. Such persons may not take jobs with high exposure to pollutants. Even if the AF for asthma-related death is overestimated, it will not change the major findings as rather few persons die from asthma.

For primary preventive work, the study highlights common factors as important for the prevention of workrelated deaths, namely, job strain, working irregular working hours, exposure to air pollutants such as motor exhaust, combustion products, and dust (eg, causing COPD).

Estimates of work-related deaths have to be based on models and assumptions both about which diseases are work-related and patterns of exposure and their variability over time. Usually there are gaps both in knowledge about exposure (eg, by lack of representative measurements) and uncertainties in dose-response relationships. Therefore, estimates of numbers are just an indication of magnitudes. We have prioritized methods that are easy to repeat and avoided complex models to make it possible for the readers themselves to judge possible influence and size of other assumptions. For example, our estimates are too low for cardiovascular disease if you consider chronic IHD to be work-related to some extent. When we have had alternatives, we have usually used estimates that tend to underestimate the number of work-related deaths. Our findings are results from exposure sometimes several decades ago, eg, for asbestos-related cancer. If the findings are used for prioritizing preventive work, such issues must be kept in mind when considering the preventive potential for the studied factors.

We have included acute myocardial infarction, cancer and respiratory diseases in our analysis and used rather conservative estimates. Adding the 75 fatal occupational accidents in 2007 to the numbers, it seems reasonable to conclude that at least around 900 deaths (3.6\%) are work-related each year in Sweden among individuals aged $25-74$ years.

\section{Acknowledgement}

This study was supported through a grant from the Swedish Work Environment Authority. We acknowledge valuable comments and discussions with Maria Albin, Per Gustavsson, and Kjell Toren.

\section{References}

1. Hamalainen P, Saarela K, Takala J. Global trend according to estimated number of occupational accidents and fatal work-related diseases at region and country level. J Safety Res. 2009;40(2):125-39. http://dx.doi.org/10.1016/j. jsr.2008.12.010.

2. Nurminen M, Karjalainen A. Epidemiologic estimate of the proportion of fatalities related to occupational factors in Finland. Scand J Work Environ Health. 2001;27(3):161-213. http://dx.doi.org/10.5271/sjweh.605.

3. Rushton L, Bagga S, Bevan R, Brown TP, Cherrie JW, Holmes $\mathrm{P}$, et al. Occupation and cancer in Britain. Br J Cancer. 2010;102(9):1428-37. http://dx.doi.org/10.1038/ sj.bjc. 6605637.

4. Cancerkommittén. Cancer: causes and prevention. London: Taylor \& Francis; 1992.

5. Gustavsson P, Jakobsson R, Johansson H, Lewin F, Norell $\mathrm{S}$, Rutkvist LE. Occupational exposures and squamous cell carcinoma of the oral cavity, pharynx, larynx, and oesophagus: a case-control study in Sweden. Occup Environ Med. 1998;55(6):393-400. http://dx.doi.org/10.1136/oem.55.6.393.

6. Torén K, Blanc PD. Asthma caused by occupational exposures is common - a systematic analysis of estimates of the population-attributable fraction. BMC Pulm Med. 2009;9:7. http://dx.doi.org/10.1186/1471-2466-9-7.

7. Balmes J, Becklake M, Blanc P, Henneberger P, Kreiss $\mathrm{K}$, Mapp C, et al. American Thoracic Society Statement: Occupational contribution to the burden of airway disease. Am J Respir Crit Care Med. 2003;167(5):787-97. http://dx.doi. org/10.1164/rccm.167.5.787.

8. Rosengren A, Hawken S, Ounpuu S, Sliwa K, Zubaid M, Almahmeed WA, et al. Association of psychosocial risk factors with risk of acute myocardial infarction in 11119 cases and 13648 controls from 52 countries (the INTERHEART study): case-control study. Lancet. 2004;364(9438):953-62. http:// dx.doi.org/10.1016/S0140-6736(04)17019-0. 
9. Belkic KL, Landsbergis PA, Schnall PL, Baker D. Is job strain a major source of cardiovascular disease risk? Scand J Work Environ Health. 2004;30(2):85-128. http://dx.doi.org/10.5271/sjweh.769.

10. Eller NH, Netterstrøm B, Gyntelberg F, Kristensen TS, Nielsen F, Steptoe A, et al. Work-related psychosocial factors and the development of ischemic heart disease: a systematic review. Cardiol Rev. 2009;17(2):83-97. http://dx.doi.org/10.1097/ CRD.0b013e318198c8e9.

11. Brook RD, Rajagopalan S, Pope CA, Brook JR, Bhatnagar A, Diez-Roux AV, et al. Particulate matter air pollution and cardiovascular disease: An update to the scientific statement from the American Heart Association. Circulation. 2010;121(21):2331-78. http://dx.doi.org/10.1161/ CIR.0b013e3181dbece1.

12. Fang SC, Cassidy A, Christiani DC. A systematic review of occupational exposure to particulate matter and cardiovascular disease. Int J Environ Res Public Health. 2010;7(4):1773-806. http://dx.doi.org/10.3390/ijerph7041773.

13. Suadicani P, Hein HO, Gyntelberg F. Occupational noise exposure, social class, and risk of ischemic heart disease and all-cause mortality - a 16-year follow-up in the Copenhagen Male Study. Scand J Work Environ Health. 2012;38(1):19-26. http://dx.doi.org/10.5271/sjweh.3200.

14. Gustavsson P, Plato N, Hallqvist J, Hogstedt C, Lewné M, Reuterwall $\mathrm{C}$, et al. A population-based case-referent study of myocardial infarction and occupational exposure to motor exhaust, other combustion products, organic solvents, lead, and dynamite. Stockholm Heart Epidemiology Program (SHEEP) Study Group. Epidemiology. 2001;12(2):222-8. http://dx.doi.org/10.1097/00001648-200103000-00015.

15. Knutsson A, Hallquist J, Reuterwall C, Theorell T, Akerstedt T. Shiftwork and myocardial infarction: a case-control study. Occup Environ Med. 1999;56(1):46-50. http://dx.doi. org/10.1136/oem.56.1.46.

16. Reuterwall C, Hallqvist J, Ahlbom A, De Faire U, Diderichsen F, Hogstedt C, et al. Higher relative, but lower absolute risks of myocardial infarction in women than in men: analysis of some major risk factors in the SHEEP study. The SHEEP Study Group. J Intern Med. 1999;246(2):161-74. http://dx.doi. org/10.1046/j.1365-2796.1999.00554.x.

17. Rosenlund M, Berglind N, Gustavsson A, Reuterwall C, Hallqvist J, Nyberg F, et al. Environmental tobacco smoke and myocardial infarction among never-smokers in the Stockholm Heart Epidemiology Program (SHEEP). Epidemiology. 2001;12(5):558-64. http://dx.doi.org/10.1097/00001648200109000-00016.

18. Levin ML, Bertell R. RE: "simple estimation of population attributable risk from case-control studies". Am J Epidemiol. 1978;108(1):78-9.

19. Gustavsson P, Jakobsson R, Nyberg F, Pershagen G, Järup L, Schéele P. Occupational exposure and lung cancer risk: a population-based case-referent study in Sweden. Am J Epidemiol. 2000;152(1):32-40. http://dx.doi.org/10.1093/ aje/152.1.32.

20. Järvholm B, Larsson S, Hagberg S, Olling S, Ryd W, Torén K. Quantitative importance of asbestos as a cause of lung cancer in a Swedish industrial city: a case-referent study. Eur Respir J. 1993;6(9):1271-5.

21. Damber LA, Larsson LG. Occupation and male lung cancer: a case-control study in northern Sweden. Br J Ind Med. 1987;44(7):446-53.

22. Dave SK, Edling C, Jacobsson P, Axelson O. Occupation, smoking, and lung cancer. Br J Ind Med. 1988;45(11):790-2.

23. Axelson O. Alternative for estimating the burden of lung cancer from occupational exposures--some calculations based on data from Swedish men. Scand J Work Environ Health. 2002;28(1):58-63. http://dx.doi.org/10.5271/sjweh.647.

24. Darnton AJ, McElvenny DM, Hodgson JT. Estimating the number of asbestos-related lung cancer deaths in Great Britain from 1980 to 2000. Ann Occup Hyg. 2006;50(1):29-38. http:// dx.doi.org/10.1093/annhyg/mei038.

25. The work environment 2009. Stockholm: Sweidish Work Envionment Authority; 2009.

26. The Work Environmnet 2007. Stockholm: The Swedish Work Environment Authority; 2008.

27. Consonni D, De Matteis S, Lubin JH, Wacholder S, Tucker M, Pesatori AC, et al. Lung cancer and occupation in a populationbased case-control study. Am J Epidemiol. 2010;171(3):32333. http://dx.doi.org/10.1093/aje/kwp391.

28. Driscoll T, Nelson DI, Steenland K, Leigh J, ConchaBarrientos M, Fingerhut M, et al. The global burden of disease due to occupational carcinogens. Am J Ind Med. 2005;48(6):419-31. http://dx.doi.org/10.1002/ajim.20209.

29. Bergdahl IA, Torén K, Eriksson K, Hedlund U, Nilsson $\mathrm{T}$, Flodin R, et al. Increased mortality in COPD among construction workers exposed to inorganic dust. Eur Respir J. 2004;23(3):402-6. http://dx.doi.org/10.1183/09031936.04.0 0034304

30. Blanc PD, Torén K. Occupation in chronic obstructive pulmonary disease and chronic bronchitis: an update. Int J Tuberc Lung Dis. 2007;11(3):251-7.

31. O’Donnell MJ, Xavier D, Liu L, Zhang H, Chin SL, RaoMelacini P, et al. Risk factors for ischaemic and intracerebral haemorrhagic stroke in 22 countries (the INTERSTROKE study): a case-control study. Lancet. 2010;376(9735):112-23. http://dx.doi.org/10.1016/S0140-6736(10)60834-3.

32. Doll R, Peto R. The causes of cancer: quantitative estimates of avoidable risks of cancer in the United States today. J Natl Cancer Inst. 1981;66(6):1191-308.

Received for publication: 2 November 2012 